\title{
LIBERDADE DE EXPRESSÃO NA INTERNET: ALGUNS PARÂMETROS INTERNACIONAIS E O DIREITO BRASILEIRO
}

\author{
FREEDOM OF EXPRESSION ON THE INTERNET: SOME INTERNATIONAL \\ STANDARDS AND THE BRAZILIAN LAW \\ Leonardo Valles Bento \\ Unidade de Ensino Superior Dom Bosco - UNDB - São Luís - Maranhão - Brasil
}

\begin{abstract}
Resumo: $O$ artigo tem por escopo explorar alguns princípios internacionalmente reconhecidos sobre liberdade de expressão aplicados à Internet, bem como pontuar brevemente a aderência ou não do direito brasileiro a estes princípios. A pesquisa se vale de relatórios produzidos pelo Conselho de Direitos Humanos das Nações Unidas e da Comissão de Direitos Humanos da Organização dos Estados Americanos, eventualmente em conjunto com outras organizações internacionais. São analisados o princípio da neutralidade da rede, a legitimidade de utilização de filtros e bloqueios de conteúdo da Internet, e o problema da responsabilização dos intermediários por conteúdos gerados e/ou publicados por terceiros. A pesquisa constatou que o direito brasileiro tem avançado na aderência aos princípios defendidos pelos referidos organismos internacionais, especialmente após o surgimento do Marco Civil da Internet (Lei no 12.965/2014).
\end{abstract}

Palavras-chaves: Internet - Lei 12.965/2014 - liberdade de expressão.

Abstract: The article scope is to explore some internationally recognized principles on freedom of expression applied to the Internet, as well to point out the adherence or not of Brazilian legal system to these principles. The research works on reports produced by the United Nations Human Rights Council and the Human Rights Commission of the Organization of American States, eventually together with other international organizations. The aspects analyzed are the principle of net neutrality, the legitimacy of using filters and blocks of Internet content, and the problem of intermediaries responsabilities for content generated or published by third users. The research found out that Brazilian law has advanced in adherence to the principles defended by these international bodies, especially after the approval of the Internet "Marco Civi" ( Law №. 12.965/2014).

Key Words: freedom of expression - Internet - Law no 12.965/2014. 


\section{Considerações iniciais}

O presente artigo tem por objetivo explorar alguns dos princípios internacionalmente reconhecidos sobre liberdade de expressão aplicados à Internet, bem como pontuar brevemente a aderência ou não do direito brasileiro a estes princípios. $O$ trabalho se vale de relatórios produzidos pelo Conselho de Direitos Humanos das Nações Unidas (ONU) e da Comissão de Direitos Humanos da Organização dos Estados Americanos (OEA), eventualmente em conjunto com outras organizações internacionais.

Naturalmente, a Internet constitui-se numa tecnologia de informação e comunicação radicalmente inovador, que revela diversos aspectos desafiadores, e não é possível dar conta de todos eles no espaço de um artigo, de modo que apenas alguns deles foram selecionados. O tópico inicial do artigo visa expor brevemente o fundamento do direito humano à liberdade de expressão, sua função em sociedades democráticas e o impacto da Internet na sua compreensão. O tópico seguinte é dedicado ao princípio da neutralidade da rede, como garantia de isonomia na gestão do tráfego na rede, de modo que o conteúdo que nela circule seja produto das escolhas dos usuários e não das empresas provedoras. O terceiro tópico trata da possibilidade e limites da censura na Internet, isto é, da utilização pelas autoridades públicas de mecanismos de filtros ou bloqueios de conteúdo na rede. O tópico posterior trata da responsabilidade civil dos intermediários, aspecto crucial para a defesa da liberdade de expressão, e ao mesmo tempo desafiador, uma vez que a arquitetura da Internet é essencialmente privada, de modo que os usuários dependem dos serviços de empresas provedoras para se expressarem livremente na rede. O regime de responsabilização dos intermediários, se não estiver em sintonia com o desenho específico da Internet, pode exercer pressão sobre essas empresas no sentido de cercear a liberdade dos usuários de publicar conteúdo.

O artigo não tratará da questão do acesso universal à Internet, isto é, da necessidade de políticas públicas tendentes a reduzir a exclusão digital. Embora seja um aspecto muito enfatizado pelas organizações internacionais, especialmente a OEA, o presente artigo prefere se focar nos princípios 
protetivos da liberdade de expressão contra a intervenção indevida, seja por parte do Estado, ou de empresas. $O$ artigo também não trata do complexo tema da proteção dos direitos autorais e da responsabilidade na sua violação, dada a necessidade de limitar o escopo do trabalho.

Ao final, o artigo pretende oferecer ao leitor um panorama acerca da visão das principais organizações internacionais acerca da liberdade de expressão aplicada à Internet e da convergência do direito brasileiro para essa mesma visão.

\section{Liberdade de expressão e Internet}

A liberdade de pensamento e de expressão constitui parte fundamental do arcabouço institucional das sociedades democráticas. O Sistema Interamericano de Proteção dos Direitos Humanos ${ }^{1}$ tem dedicado significativo esforço ao desenvolvimento doutrinário sobre esse tema, definindo princípios, compilando as melhores práticas observadas no continente, denunciando situações de abuso e violações desse direito e, também, por meio da jurisprudência da Corte, determinando aos países membros da OEA a reparação às vítimas e a efetivação de políticas de proteção, além de consolidar, por meio dos fundamentos das decisões, o marco jurídico da liberdade de expressão como direito humano.

A liberdade de expressão tem como fundamento uma tripla função que ela desempenha em sociedades livres.

Em primeiro lugar, trata-se de um dos direitos individuais que mais claramente reflete as características únicas dos seres humanos: a capacidade de pensar o mundo a sua volta desde sua própria perspectiva, e a capacidade de comunicar-se com outros, expressando e intercambiando ideias, experiências de vida e visões de mundo. Desse modo, por meio de um processo dialético e deliberativo, o ser humano constrói coletivamente sua

\footnotetext{
1 O Sistema Interamericano de Proteção dos Direitos Humanos (SIPDH) é formado pela Comissão Interamericana de Direitos Humanos (Comissão ou CIDH) e pela Corte Interamericana de Direitos Humanos (Corte), ambos órgãos da Organização dos Estados Americanos, com atribuições fixadas pela Convenção Americana de Direitos Humanos. Dentro da Comissão funciona a Relatoria Especial para a Liberdade de Expressão, encarregada de assessorar a CIDH sistematizando a jurisprudência e o conhecimento acerca do direito à liberdade de expressão e, desde 1998, divulga informes anuais, além de diversas outras publicações temáticas. (< http://www.oas.org/es/cidh/expresion/index.asp $>$ )
} 
representação da realidade e decide os termos de sua vida comunitária. Além disso, todo o potencial criativo na arte, na ciência, na tecnologia e na política depende do gozo efetivo da liberdade humana de expressar-se em todas as suas dimensões (ORGANIZACIÓN DE LOS ESTADOS AMERICANOS, 2009, p. 2).

Em segundo lugar, a liberdade de pensamento e de expressão possui uma relação estrutural com a democracia. A democracia pode ser definida como um sistema político no qual os cidadãos decidem, diretamente ou por meio de seus representantes, os assuntos da coletividade, e no qual as autoridades públicas prestam contas das suas ações. Nos termos do princípio do discurso de Habermas, a democracia e a ideia correlata de autogoverno - a autodeterminação política da coletividade fundada sobre a autonomia moral de seus membros - pressupõe decisões livres de coerção, legitimadas por um diálogo racional entre sujeitos iguais, no qual prevalece apenas a força do melhor argumento. No entanto, tais decisões, livres de relações de poder e dominação, exigem um conjunto de condições sociopsicológicas para a formação racional da opinião e da vontade, condições que se traduzem em um sistema de direitos fundamentais. O papel da liberdade de expressão, nesse sistema, consiste em permitir aos participantes da vida pública expressar-se, questionar, argumentar, criticar e contestar livremente (HABERMAS, 1997).

Esse é também o posicionamento da Comissão Interamericana de Direitos Humanos. Segundo ela, o objetivo do art. 13 da Convenção Interamericana é fortalecer o funcionamento de sistemas democráticos pluralistas e deliberativos, protegendo a livre circulação de ideias e opiniões de toda índole, viabilizando um processo deliberativo aberto e desimpedido, sobre todos os assuntos que dizem respeito aos interesses da sociedade. A formação de uma opinião pública bem informada e consciente dos seus direitos, bem como a responsabilização de autoridades públicas, não seriam possíveis de outro modo (ORGANIZACIÓN DE LOS ESTADOS AMERICANOS, 2009, p. 3).

Em terceiro lugar, a liberdade de expressão é um instrumento para a defesa de outros direitos, tais como o direito de reunião e associação, de participação política, o direito à educação, à liberdade religiosa, e à identidade étnica e cultural (ORGANIZACIÓN DE LOS ESTADOS AMERICANOS, 2009, p. 4). 
Portanto, a liberdade de expressão não deve ser entendida apenas em um sentido individual, mas também como um direito difuso. Como direito individual, a liberdade de expressão consiste no direito de cada pessoa expressar livremente seus pensamentos, ideias e informações. Como direito difuso, trata-se do direito de a sociedade obter e receber informações, livre de interferência e obstáculos, dos pensamentos, ideias, opiniões e informações dos outros. Assim, a liberdade de expressão constitui-se em instrumento de intercâmbio e comunicação entre todos os seres humanos. Conhecer o pensamento do outro é tão importante quanto exprimir o próprio.

Nesse sentido, o surgimento da Internet representou a possibilidade, num grau nunca antes imaginado, de realização plena do direito de expressarse livremente e do direito à livre circulação da informação. Conforme ressalta a Comissão Interamericana de Direitos Humanos, "[a] Internet, como nenhum meio de comunicação existente antes, permitiu aos indivíduos comunicar-se instantaneamente e a baixo custo, e teve um impacto dramático no jornalismo e na forma como compartilhamos e acessamos informações e ideias" (ORGANIZACIÓN DE LOS ESTADOS AMERICANOS, 2013, p. 5). Principalmente com o surgimento de blogs e redes sociais, subverteu-se a separação entre produtor e receptor de informações. Todos podem ser jornalistas, formadores de opinião e editores de conteúdo. Conforme também ressalta o Relator Especial para Liberdade de Opinião e Expressão das Nações Unidas:

\begin{abstract}
Diferente de qualquer outro meio de comunicação, tais como rádio, televisão e publicações impressas, baseadas na transmissão unidirecional de informação, as pessoas não são mais destinatários passivos, mas também editores ativos de informação. Essas plataformas são particularmente valiosas em países onde não há meios de comunicação independentes, na medida em que permitem aos indivíduos compartilhar pontos de vista críticos e obter a informação objetiva. Além disso, os produtores de mídia tradicional também podem usar a Internet para expandir grandemente as suas audiências a um custo nominal (tradução livre, UNITED NATIONS, 2011, p. 6-7) ${ }^{2}$.
\end{abstract}

\footnotetext{
2 "Unlike any other medium of communication, such as radio, television and printed publications based on one-way transmission of information, individuals are no longer passive recipients, but also active publishers of information. Such platforms are particularly valuable in countries where there is no independent media, as they enable individuals to share critical views and to find objective information. Furthermore, producers of traditional media can also use the Internet to greatly expand their audiences at nominal cost".
} 
O grande potencial da Internet decorre de suas características únicas, em especial a velocidade, alcance global e relativo anonimato. Essas características capacitam indivíduos para disseminar informação em tempo real e mobilizar pessoas para empreender ações de todo tipo, inclusive políticas, o que vem assustando governos e autoridades administrativas. As características da Internet - um espaço radicalmente aberto, descentralizado e plural resultam de sua arquitetura em rede, desprovida de um centro. Ela se desenvolveu a partir de princípios enraizados no seu desenho e é de suma importância que qualquer marco regulatório preserve esses princípios e leve em conta essa arquitetura. Por tudo isso, não se pode tratar a internet da mesma forma que são tratados outros meios de comunicação (ORGANIZACIÓN DE LOS ESTADOS AMERICANOS, 2013, p. 5-6).

No entanto, nenhum direito fundamental é absoluto. Existem motivos legítimos, relacionados com a proteção à segurança coletiva e a outros direitos de igual dignidade, para relativizar os direitos. Em caso de colisão entre a liberdade de expressão e outros valores igualmente merecedores de proteção, costuma-se aplicar um teste de razoabilidade das medidas restritivas. Assim, da mesma forma, restrições à liberdade na Internet somente serão legítimas se atenderem concomitantemente a um conjunto de requisitos exigentes, quais sejam:

(1) Excepcionalidade e previsão legal, isto é, as restrições devem ser exceções taxativamente previstas em uma lei, em sentido formal e material, especificadas em linguagem clara e objetiva, e que deve ser interpretadas restritivamente.

(2) Adequação, ou seja, as restrições devem visar a uma finalidade legítima e serem de fato capazes de promover essa finalidade. As finalidades legitimamente reconhecidas pelas declarações internacionais de direitos são proteger a reputação de outros indivíduos e proteger a segurança nacional, a ordem ou a saúde pública.

(3) Necessidade, isto é, a liberdade de expressão na Internet somente deve ser restringida no que for estritamente necessário ao atingimento dos objetivos visados na restrição, após a consideração cuidadosa de outras alternativas menos restritivas. 
(4) Proporcionalidade, ou seja, uma relação positiva entre os benefícios esperados pela restrição em comparação com o sacrifício imposto à liberdade de expressão.

(5) Possibilidade de revisão por uma autoridade independente, de acordo com devido processo legal: qualquer decisão que restringe o direito à liberdade de expressão deve ser aplicada por uma autoridade independente de quaisquer influências indevidas, sejam políticas, comerciais, ou outras, de forma que não seja arbitrária, nem discriminatória, e com salvaguardas adequadas contra $\mathrm{o}$ abuso, incluindo a possibilidade de contestação e invalidação contra a sua aplicação abusiva (UNITED NATIONS, 2011, p. 8; ORGANIZACIÓN DE LOS ESTADOS AMERICANOS, 2009, p. 22-30).

Tais requisitos devem ser levados em conta na formulação dos marcos regulatórios sobre o uso da Internet, cujos aspectos serão desenvolvidos nos tópicos seguintes. De acordo com o Relator Especial das Nações Unidas para Liberdade de Opinião e Expressão, os tipos legítimos de informações que podem ser limitados incluem pornografia infantil, discursos de ódio, difamação (a fim de proteger os direitos e da reputação de outrem contra ataques injustificados), incitamento direto e público à prática de genocídio, e apologia ao ódio nacional, racial ou religioso que constitua incitamento à discriminação, à hostilidade ou à violência (UNITED NATIONS, 2011, p. 8).

\section{Princípio da neutralidade da rede}

Para que o usuário possa utilizar a Internet, são necessários dois tipos de serviço: o serviço de conexão e os serviços de conteúdo. O primeiro serviço consiste na disponibilização ao usuário de um meio de transmissão, com ou sem fio, e uma identidade de acesso, um endereço lógico na rede, conhecido pelo número de Protocolo de Internet, ou IP. Uma vez estabelecida a conexão, os serviços de conteúdo oferecem à escolha do usuário os mais diversos serviços e aplicações.

Originariamente, a Internet foi pensada para ser um ambiente neutro em relação ao conteúdo que nela circula. Toda informação que circula na rede é fragmentada em inúmeros pacotes de dados, os quais não necessariamente viajarão pelo mesmo caminho. A rede fornece diversas rotas de transmissão 
desses pacotes, que são remontados no seu destino final. O princípio da neutralidade da rede estabelece que todos os pacotes de informações que circulam na rede devem ser tratados de forma isonômica, isto é, devem trafegar na mesma velocidade, sem discriminação em razão de fatores como tipo de conteúdo, autor, origem, destino, serviço ou aplicação (ORGANIZACIÓN DE LOS ESTADOS AMERICANOS, 2011, p. 5).

Trata-se, segundo seus defensores, de um princípio de democracia na rede. A ideia é que a informação que circula na Internet seja um reflexo das escolhas livres dos usuários, e não das empresas provedoras de conexão ou de conteúdo. O debate acerca da neutralidade da rede originou-se de mais de um fator. Em primeiro lugar, provedores de serviços de telefonia e de conexão à Internet foram prejudicados com o surgimento de serviços tais como o de Voz sobre IP (VolP), que permite a conversação através da Internet sem nenhum pagamento adicional.

Em segundo lugar, uma vez que a Internet possui três personagens ( 0 provedor de conexão, o provedor de conteúdo e o usuário), não demorou para que surgisse um novo mercado para a qualidade do serviço de Internet (QoS). Empresas produtoras de conteúdo passaram a pagar mais aos provedores de conexão para que o seu conteúdo trafegasse de forma mais rápida pela rede. Isso favorece o predomínio de grandes empresas que, graças ao seu poder econômico, atrairiam mais usuários graças à qualidade da conexão, mesmo que o seu conteúdo não seja o melhor ou que não seja aquele que o usuário naturalmente escolheria em condições isonômicas.

Em terceiro lugar, o desenvolvimento da Internet acarretou o surgimento de diversos serviços e aplicações que exigem muita largura de banda, ou que exigem comunicação em tempo real, em particular a já mencionada telefonia VolP, o compartilhamento de arquivos Pier-to-Pier (P2P), ou torrent, serviços de mensagem instantânea (tais como Whatsapp) e o serviço de vídeo streaming, tais como YouTube ou o Netflix. Tais aplicações não são capazes de funcionar a menos que Ihes seja garantido um mínimo de qualidade de serviço. Esse terceiro aspecto é particularmente importante, pois tem levado algumas legislações a flexibilizar o princípio da neutralidade da rede.

Um caso bem conhecido é o da empresa Netflix, que permite a seus clientes assistirem filmes e séries de TV pela Internet. Para que o seu serviço 
funcione, é fundamental que não haja congestionamento na transmissão dos dados. Do contrário, a transmissão do conteúdo sofrerá repetidas interrupções, prejudicando a qualidade e irritando o usuário. A empresa celebrou acordos com as principais provedoras de conexão dos Estados Unidos, a Varizon e a Comcast para que estas the disponibilizassem uma pista livre para a transmissão dos seus pacotes de dados, numa aparente flexibilização ao princípio em comento. De fato, esse tipo de acordo permite que empresas economicamente poderosas, como a Netflix, paguem por uma velocidade de conexão maior, atraindo assim a preferência dos usuários, em detrimento de outras empresas menores que oferecem o mesmo serviço, prejudicando assim a competitividade (FELITI, 2014).

Convém destacar que o princípio da neutralidade da rede somente se torna relevante em situações de congestionamento do tráfego na Internet, isto é, quando o excesso de informação circulante provoca lentidão na rede. Quando a banda é suficientemente espaçosa para permitir o fluxo livre de todo o conteúdo, não há necessidade de se adotar regras para a gestão do tráfego. O princípio em comento postula que o tráfego deve ser administrado de forma isonômica e não discriminatória.

No entanto, como se viu acima, há situações que requerem uma flexibilização desse princípio. No caso do Brasil, a Lei no 12.965/2014 (Marco Civil da Internet), após afirmar a garantía do princípio da neutralidade em seus

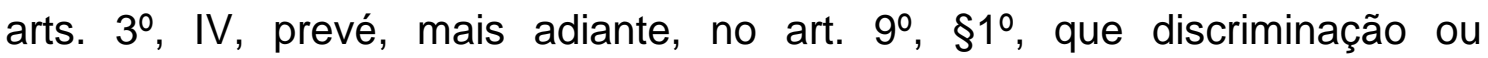
degradação do tráfego é possível quando decorrer de: (I) requisitos técnicos indispensáveis à prestação adequada de serviços e aplicações; e (II) priorização de serviços de emergência. O dispositivo legal citado ainda exige que estas exceções sejam regulamentadas por meio de Decreto do Presidente da República, ouvidos o Comitê Gestor da Internet e a Agência Nacional de Telecomicações.

De acordo com a Declaração Conjunta sobre Liberdade de Expressão e Internet, aprovada pelo Relator Especial das Nações Unidas (ONU) para a Liberdade de Opinião e Expressão, pelo Representante para a Liberdade dos Meios de Comunicação da Organização para a Segurança e Cooperação na Europa (OSCE), pelo Relator Especial da Organização dos Estados Americanos (OEA) para a Liberdade de Expressão e do Relator Especial sobre 
a Liberdade de Expressão e Acesso à Informação da Comissão Africana dos Direitos Humanos e dos Povos (CADHP):

Deve-se exigir dos intermediários de Internet que sejam transparentes em relação às práticas que empregam para a gestão do tráfego ou da informação e qualquer informação relevante sobre tais práticas deve ser posta a disposição do público em um formato que resulte acessível para todos os interessados (tradução livre, ORGANIZACIÓN DE LOS ESTADOS AMERICANOS, 2011, p. 5). ${ }^{3}$

Portanto, exceções ao princípio são permitidas, desde que devidamente regulamentadas, de forma transparente e visando objetivos legítimos, de modo a não desvirtuar, nem tornar inócuo, o princípio em comento, transformando o que deveria ser a regra geral em exceção.

\section{Filtros e bloqueios}

Conforme dito acima, as restrições à liberdade de expressão na Internet devem respeitar requisitos exigentes de razoabilidade. Em primeiro lugar, tais restrições devem ser excepcionais e taxativamente previstas em Lei, aprovada pelo Poder Legislativo, a qual deverá descrever as hipóteses de restrição de forma clara e objetiva, reduzindo ao mínimo a discricionariedade das autoridades públicas na sua interpretação. Além disso, quanto ao mérito, tais hipóteses de restrição devem passar em um teste tripartite de adequação, necessidade e proporcionalidade. Por fim, as decisões das autoridades públicas que determinem uma restrição à liberdade de expressão devem ser passíveis de recurso e de revisão por autoridades independentes.

Este teste tripartite aplica-se de forma típica às situações em que os governos impõem bloqueio ou suspensão compulsória de sítios da Internet, ou determina a remoção de conteúdo de sítios ou de motores de busca. Tais medidas somente se admitem em casos excepcionais, relacionados com a prática de atos claramente ilícitos, ou com a disseminação de discursos não protegidos pelo direito à liberdade de expressão. Como exemplos de situações

\footnotetext{
3 "Se debe exigir a los intermediarios de Internet que sean transparentes respecto de las prácticas que emplean para la gestión del tráfico o la información, y cualquier información relevante sobre tales prácticas debe ser puesta a disposición del público en un formato que resulte accesible para todos los interesados".
} 
passíveis de bloqueio são a pornografia infantil, a apologia ao crime e à violência, ou os chamados discursos de ódio, que incitam ao ódio étnico, político, religioso ou outro qualquer (ORGANIZACIÓN DE LOS ESTADOS AMERICANOS, 2013, p. 46).

Convém destacar que essa medida de censura somente pode atingir conteúdos específicos, conforme avaliação de sua ilicitude no caso concreto, e deve ser cuidadosamente desenhada de tal forma que não atinja os conteúdos lícitos do mesmo sítio.

\begin{abstract}
Indispensável, pois, que o pedido de exclusão dos resultados de pesquisa de um texto ou imagem específica seja formulado judicialmente. A despeito disso, mesmo mediante expressa ordem judicial, seria indispensável que o conteúdo a ser excluído viesse acompanhado da indicação do respectivo URL (sigla que corresponde à expressão Universal Resource Locator, que em português significa localizador universal de recursos. [...] [Os provedores de pesquisa] não podem ser obrigados a eliminar do seu sistema os resultados derivados da busca de determinado termo ou expressão, tampouco os resultados que apontem para uma foto ou texto específico, independentemente da indicação do URL da página em que este estiver inserido. (ANDRIGHI, 2012, p. 72-74).
\end{abstract}

De fato, também os mandatários especiais para liberdade de expressão da OEA, da ONU, da Organização para Segurança e Cooperação na Europa (OSCE) e da União Africana, por meio da Declaração Conjunta sobre Liberdade de Expressão e Internet, de 2012, item 3 "a", afirmaram que o bloqueio de sítios web inteiros, endereços e IP, ou redes sociais constitui uma medida extrema equivalente à proibição de um jornal ou emissora de rádio ou TV (ORGANIZACIÓN DE LOS ESTADOS AMERICANOS, 2011).

Além disso, as medidas de bloqueio devem ser determinadas por uma autoridade competente, atendendo ao devido processo legal, que inclui a possibilidade de revisão por uma autoridade independente. A decisão deve ser transparente quanto ao seu fundamento, de modo que as hipóteses devem ser reguladas em lei e as decisões motivadas com base nela. A motivação da medida de bloqueio deve abordar também a questão da necessidade, isto é, deve provar que é a única medida possível, ou a menos restritiva, para alcançar uma finalidade legal e legítima. Em outras palavras, as medidas de filtro ou bloqueio devem seguir os requisitos já expostos anteriormente: previsão legal, adequação, necessidade, proporcionalidade, aplicação por uma 
autoridade independente, possibilidade de impugnação e devido processo legal.

Já no que tange aos conteúdos que sejam impróprios para crianças, tais como sites de pornografia ou de violência, considera-se abusivo que as medidas de filtro ou bloqueio sejam tornadas obrigatórias ou efetuadas diretamente por governos, cabendo exclusivamente ao usuário, no caso os pais ou responsáveis, avaliar a necessidade de tais filtros e de que forma implementá-los (ORGANIZACIÓN DE LOS ESTADOS AMERICANOS, 2013, p. 41).

Uma das formas mais comuns de abuso na utilização das medidas de filtro ou bloqueio consiste na alegação de preservar a ordem pública, especialmente diante de denúncias de escândalos de corrupção, a divulgação de pesquisas que tragam indicadores econômicos, sociais ou ambientais negativos, notícias sobre a disseminação de doenças e catástrofes naturais, etc. Outro exemplo é o bloqueio de acesso a redes sociais quando são utilizadas para mobilizar pessoas para uma manifestação pública ou um protesto. Tais discursos recebem uma proteção especial, em face da liberdade de expressão, não se admitindo o bloqueio ou filtro à sua livre circulação. De acordo com o Relatório Especial das Nações Unidas para a Liberdade de Opinião e Expressão há uma crescente preocupação com a tendência de bloqueios just-in-time de redes sociais e blogs, isto é, de impedir usuários de acessar esses serviços em momentos cruciais, tais como durante eleições, protestos, ou em datas comemorativas de eventos históricos (UNITED NATIONS, 2011, p. 9-10).

\section{Responsabilização dos intermediários}

Uma das características específicas da Internet é que a interação entre os usuários se dá por intermédio de uma pluralidade de atores, chamados genericamente de intermediários. São os provedores de acesso e conexão, os prestadores de serviço de hospedagem de conteúdo publicado pelo usuário (websites ou blogs), serviços de busca de conteúdo (como o Google),

programas de navegação, e plataformas de redes sociais (tais como o Facebook, Twitter, Orkut, Linkdln, etc.). 
O interesse na atuação dos intermediários tornou-se relevante em razão de que através deles é tecnicamente possível exercer controle sobre os conteúdos divulgados na Internet. Tanto governos quanto cidadãos e empresas têm se voltado para esses intermediários no sentido de obrigá-los a monitorar a publicação de conteúdo e proceder à remoção do mesmo, sempre que se sentem prejudicados. Muitas razões explicam isso. Em primeiro lugar, a quantidade de usuários da Internet é imensa e muitos deles acessam a rede e publicam conteúdo anonimamente ou por meio de pseudônimos, tornando difícil a identificação do autor do conteúdo ofensivo. Em segundo lugar, devido ao caráter global da Internet, é possível a um usuário criar sites ou blogs em qualquer lugar do planeta, criando assim problemas de jurisdição (forum shopping). Ambos os problemas são agravados em razão de que a informação é livre e facilmente compartilhada por outros usuários. Finalmente, uma vez que normalmente os intermediários são grandes empresas, há um incentivo econômico para responsabilizá-las por conteúdo produzido por terceiros. Por todos esses motivos, é muito mais cômodo acionar judicialmente e responsabilizar o intermediário do que o efetivo autor individual da publicação ilícita ou ofensiva.

No Brasil, parte da jurisprudência tendeu inicialmente no sentido de estabelecer uma responsabilidade objetiva dos intermediários. Talvez pelo fato de que a circulação de informações na Internet é sustentada por serviços oferecidos por empresas privadas, a interpretação do regime de responsabilidade sofreu interferência do direito do consumidor, em detrimento dos princípios internacionais regentes da liberdade de expressão.

Nesse sentido, o Tribunal de Justiça de São Paulo considerou que a empresa proprietária de um site de relacionamento é responsável pelos danos decorrentes de informações inseridas por terceiros. No caso, houve divulgação dos nomes das autoras, inclusive telefone, no referido site, por terceira pessoa, atribuindo-Ihes a prática de programas sexuais. $\mathrm{O}$ mais significativo é que 0 Tribunal entendeu que a empresa prestadora do serviço teria uma obrigação de controle prévio de todas as informações ali inseridas por terceiros (SÃO PAULO, 2007).

Em outra ação movida contra a empresa Google, proprietária da rede social Orkut, terceiros criaram uma "comunidade" que divulgava a informação 
de que a empresa autora encontrava-se em estado falimentar, além de ser causadora de prejuízo a seus fornecedores. Apesar de disponibilizar um serviço de denúncia contra conteúdo impróprio e de haver retirado de circulação a informação ofensiva assim que notificada pelo usuário ofendido, o órgão julgador concluiu pela responsabilidade do provedor de serviços por não exercer um controle preventivo do conteúdo gerado por terceiros (SÃO PAULO, 2008).

Ainda em outra ação, julgada pelo Tribunal de Justiça de Minas Gerais, também contra a empresa Google, o acórdão foi mais explícito ao fundamentar a sentença na teoria do risco e no Código de Defesa do Consumidor, com vistas a imputar responsabilidade objetiva ao prestador do serviço de hospedagem de conteúdos gerados por terceiros. Neste caso, tratava-se de um blog, hospedado no domínio blogspot de propriedade do google, no qual se publicou conteúdo ofensivo à honra do autor. Assim se pronunciou o TJMG:

\begin{abstract}
EMENTA: AÇÃO DE INDENIZAÇÃO. PUBLICAÇÃO DE MATERIAL OFENSIVO NA INTERNET SEM IDENTIFICAÇÃO DO USUÁRIO. RESPONSABILIDADE DA PROVEDORA DE CONTEÚDO. DANO MORAL. ARBITRAMENTO.À medida que a Provedora de Conteúdo disponibiliza na Internet um serviço sem dispositivos de segurança e controle mínimos e, ainda, permite a publicação de material de conteúdo livre, sem sequer identificar o usuário, deve responsabilizarse pelo risco oriundo do seu empreendimento. Em casos tais, a incidência da responsabilidade objetiva decorre da natureza da atividade, bem como do disposto no art. $3^{\circ}, \S 2^{\circ}$, do Código de Defesa do Consumidor (MINAS GERAIS, 2009).
\end{abstract}

Tal interpretação é condenada enfaticamente tanto pelas organizações não governamentais que militam pela liberdade de expressão, como também por organizações internacionais como a ONU e a OEA. Na já mencionada Declaração Conjunta sobre Liberdade de Expressão e Internet, sustenta-se que:

Nenhuma pessoa que ofereça unicamente serviços técnicos de Internet, como acesso, buscas, ou conservação em memória caché deverá ser responsável por conteúdos gerados por terceiros e que se difundam através destes serviços, sempre que não intervenha especificamente nos ditos conteúdos, nem se negue a cumprir uma ordem judicial que exija sua eliminação quando esteja em condições 
de fazê-lo (princípio de mera transmissão) (tradução livre, ORGANIZACION DE LOS ESTADOS AMERICANOS, 2011) ${ }^{4}$.

O problema com a ideia de responsabilidade objetiva do intermediário, em primeiro lugar, é que ela é uma situação excepcional, somente admissível nas situações em que o responsável tem efetivo controle sobre o fator de risco que acarretou o dano. No caso da Internet, é conceitual e tecnicamente impossível, a menos que se descaracterize toda a arquitetura da rede, exigir-se que os intermediários realizem um controle preventivo de todo o conteúdo que circula em seus serviços, ou presumir que está sob seu controle evitar os danos que conteúdos impróprios possam causar a terceiros. Numa analogia bastante conhecida, é como responsabilizar o mensageiro pelo conteúdo da mensagem, ou como responsabilizar a companhia telefônica por uma ameaça recebida por telefone.

Tal exigência significaria impor aos intermediários o dever de realizar censura privada. Convém ressaltar que os intermediários, uma vez que se trata de empresas privadas, possuem finalidade lucrativa e prestam contas a seus acionistas. Sua prioridade não é maximizar a liberdade de expressão. Não são instituições vocacionadas para ponderar direitos fundamentais, nem se pode exigir delas que tomem decisões juridicamente corretas nessa matéria. Um sistema que responsabiliza os intermediários por conteúdos produzidos e publicados por usuários levará estas empresas a uma atitude hipercautelosa, visando sua autoproteção, de modo que tenderão a restringir ou a retirar conteúdos da rede que seriam perfeitamente legítimos, devido ao temor de sofrerem um processo. Na dúvida, as empresas intermediárias da Internet preferirão errar em favor da censura do que permitir conteúdos que poderá levá-las, eventualmente, a ter que pagar indenizações aos ofendidos.

O Relator Especial das Nações Unidas para Liberdade de Expressão também chama atenção ainda para o fato de que um controle prévio exercido por tais empresas intermediárias viola o direito dos usuários à liberdade de

\footnotetext{
4 "Ninguna persona que ofrezca únicamente servicios técnicos de Internet como acceso, búsquedas o conservación de información en la memoria caché deberá ser responsable por contenidos generados por terceros y que se difundan a través de estos servicios, siempre que no intervenga específicamente en dichos contenidos ni se niegue a cumplir una orden judicial que exija su eliminación cuando esté en condiciones de hacerlo (principio de mera transmisión)".
} 
expressão, sem que este tenha tido oportunidade de exercer as garantias processuais do contraditório.

Responsabilizar os intermediários pelo conteúdo difundido ou criado por seus usuários solapa gravemente o exercício da liberdade de opinião e de expressão, uma vez que conduz a uma censura privada de autoproteção excessivamente ampla, amiúde sem transparência e sem o devido processo legal (UNITED NATIONS, 2011, p. 12) ${ }^{5}$.

Pelas razões expostas acima, as organizações internacionais e não governamentais que atuam na matéria são unânimes em sustentar que a responsabilidade posterior por conteúdo ofensivo divulgado na rede somente deve ser imposta aos seus autores diretos.

Em consideração a isto, em muitos países, em particular nos Estados Unidos e na União Europeia, foram adotados um sistema conhecido como notificação e retirada (notice and take down). Esse sistema estrutura um modelo de responsabilidade subjetiva, condicionada ao cumprimento de procedimentos de notificação extrajudicial. Neste esquema, também conhecido como porto seguro, o prejudicado notifica o prestador de serviço de que um conteúdo produzido por um usuário é ofensivo e ilegal. A notificação é analisa pelo prestador do serviço que, constatando a procedência da notificação, retira o conteúdo do site, blog/rede social, etc. Nesse sistema, o intermediário somente será responsabilizado se falhar em atender a uma notificação sobre conteúdo de fato ofensivo (ORGANIZACIÓN DE LOS ESTADOS AMERICANOS, 2013, p. 49-50).

A jurisprudência brasileira tem evoluído para a utilização desse sistema. No próprio Tribunal de Justiça de Minas Gerais consta um precedente. Em ação movida contra a empresa UOL S/A, o ofendido pedia danos morais em razão de um comentário ofensivo de um leitor em uma matéria publicada pelo referido site de notícias, apesar de que a empresa ré excluiu o comentário assim que foi notificada. Desta vez, o Tribunal entendeu que não há responsabilidade do provedor de serviços por informações publicadas por

\footnotetext{
5. "Holding intermediaries liable for the content disseminated or created by their users severely undermines the enjoyment of the right to freedom of opinion and expression, because it leads to self-protective and over-broad private censorship, often without transparency and the due process of the law".
} 
terceiro e que não existe, nem é tecnicamente possível, o monitoramento prévio das publicações dos usuários:

\begin{abstract}
Em regra, o provedor de hospedagem não é responsável pelo conteúdo das informações que exibe na rede, salvo se, verificada a ocorrência de ato ilícito, se recusar a identificar o ofensor ou interromper o serviço prestado ao agente. Isso porque não há que se falar em dever legal do provedor de fiscalizar as ações de seus usuários (MINAS GERAIS, 2008).
\end{abstract}

Esta corrente jurisprudencial se consolidou no Superior Tribunal de Justiça. Embora reconhecendo a relação de consumo e a incidência das restrições do Código de Defesa do Consumidor, o STJ estabeleceu que a fiscalização prévia de conteúdo por parte do provedor de serviços na Internet não é atividade intrínseca ao serviço, não devendo, portanto, ser responsabilizado em razão da ausência desta fiscalização. A responsabilidade solidária só incide se, após ciência do ilícito, omitir-se em remover o conteúdo ofensivo. Essa regra foi reconhecida em caso de serviços de e-mail:

1. A exploração comercial da Internet sujeita as relações de consumo daí advindas à Lei no 8.07890 .

2. O fato de o serviço prestado pelo provedor de serviço de Internet ser gratuito não desvirtua a relação de consumo, pois o termo "mediante remuneração", contido no art. $3^{\circ}, \S 2^{\circ}$, do CDC, deve ser interpretado de forma ampla, de modo a incluir o ganho indireto do fornecedor.

3. O provedor de correio eletrônico (e-mail) é uma espécie do gênero provedor de conteúdo, pois propicia o envio de mensagens aos destinatários indicados pelos usuários, incluindo a possibilidade de anexar arquivos de texto, som e imagem.

4. A fiscalização prévia, pelo provedor de correio eletrônico, do conteúdo das mensagens enviadas por cada usuário não é atividade intrínseca ao serviço prestado, de modo que não se pode reputar defeituoso, nos termos do art. 14 do CDC, o site que não examina e filtra os dados e imagens encaminhados.

5. O dano moral decorrente de mensagens com conteúdo ofensivo enviadas pelo usuário via e-mail não constitui risco inerente à atividade dos provedores de correio eletrônico, de modo que não se Ihes aplica a responsabilidade objetiva prevista no art. 927, parágrafo único, do CCO2.

6. Ao ser comunicado de que determinada mensagem possui conteúdo ilícito, deve o provedor de correio eletrônico agir de forma enérgica, suspendendo a respectiva conta de e-mail, sob pena de responder solidariamente com o autor direto do dano, em virtude da omissão praticada.

7. Ao oferecer um serviço por meio do qual se possibilita que os usuários externem livremente sua opinião, deve o provedor de correio eletrônico ter o cuidado de propiciar meios para que se possa identificar cada um desses usuários, coibindo 0 anonimato e atribuindo a cada manifestação uma autoria certa e determinada. Sob 
a ótica da diligência média que se espera do provedor, deve este adotar as providências que, conforme as circunstâncias específicas de cada caso, estiverem ao seu alcance para a individualização dos usuários, sob pena de responsabilização subjetiva por culpa in omittendo (BRASIL, 2012).

Também foi reconhecida nas situações que envolvem comentários ofensivos em blogs:

1. A exploração comercial da Internet sujeita as relações de consumo daí advindas à Lei ํㅡ 8.07890.

2. O fato do serviço prestado pelo provedor de serviço de Internet ser gratuito não desvirtua a relação de consumo, pois o termo "mediante remuneração" contido no art. $3^{\circ}$, $\S 2^{\circ}$, do CDC, deve ser interpretado de forma ampla, de modo a incluir o ganho indireto do fornecedor.

3. A fiscalização prévia, pelo provedor de conteúdo, do teor das informações postadas na web por cada usuário não é atividade intrínseca ao serviço prestado, de modo que não se pode reputar defeituoso, nos termos do art. 14 do CDC, o site que não examina e filtra os dados e imagens nele inseridos.

4. O dano moral decorrente de mensagens com conteúdo ofensivo inseridas no site pelo usuário não constitui risco inerente à atividade dos provedores de conteúdo, de modo que não se thes aplica a responsabilidade objetiva prevista no art. 927, parágrafo único, do CCO2.

5. Ao ser comunicado de que determinado texto ou imagem possui conteúdo ilícito, deve o provedor agir de forma enérgica, retirando o material do ar imediatamente, sob pena de responder solidariamente com o autor direto do dano, em virtude da omissão praticada.

6. Ao oferecer um serviço por meio do qual se possibilita que os usuários externem livremente sua opinião, deve o provedor de conteúdo ter o cuidado de propiciar meios para que se possa identificar cada um desses usuários, coibindo o anonimato e atribuindo a cada manifestação uma autoria certa e determinada. Sob a ótica da diligência média que se espera do provedor, deve este adotar as providências que, conforme as circunstâncias específicas de cada caso, estiverem ao seu alcance para a individualização dos usuários do site, sob pena de responsabilização subjetiva por culpa in omittendo (BRASIL, 2010).

\section{E, por fim, em casos de mensagens ofensivas publicadas em redes}

sociais:

REDES SOCIAIS. MENSAGEM OFENSIVA. REMOÇÃO. PRAZO.

A Turma entendeu que, uma vez notificado de que determinado texto ou imagem possui conteúdo ilícito, o provedor deve retirar o material do ar no prazo de 24 horas, sob pena de responder solidariamente com o autor direto do dano, pela omissão praticada. Consignou-se que, nesse prazo (de 24 horas), o provedor não está obrigado a analisar o teor da denúncia recebida, devendo apenas promover a suspensão preventiva das respectivas páginas, até que tenha tempo hábil para apreciar a veracidade das alegações, de modo que, confirmando-as, exclua definitivamente o perfil ou, tendo-as por infundadas, restabeleça o seu livre acesso. Entretanto, ressaltou-se que o diferimento da análise do teor das denúncias não significa que 
o provedor poderá postergá-la por tempo indeterminado, deixando sem satisfação o usuário cujo perfil venha a ser provisoriamente suspenso. Assim, frisou-se que cabe ao provedor, o mais breve possível, dar uma solução final para o caso, confirmando a remoção definitiva da página de conteúdo ofensivo ou, ausente indício de ilegalidade, recolocá-la no ar, adotando, na última hipótese, as providências legais cabíveis contra os que abusarem da prerrogativa de denunciar. Por fim, salientou-se que, tendo em vista a velocidade com que as informações circulam no meio virtual, é indispensável que sejam adotadas, célere e enfaticamente, medidas tendentes a coibir a divulgação de conteúdos depreciativos e aviltantes, de sorte a reduzir potencialmente a disseminação do insulto, a fim de minimizar os nefastos efeitos inerentes a dados dessa natureza (BRASIL, 2012a).

Em outras palavras, o STJ parece ter aderido ao sistema do notice and take down, pelo qual o intermediário é isento de responsabilidade por informações produzidas ou publicadas por terceiros enquanto não for notificado do seu caráter ofensivo ou ilegal. Porém, a partir do momento em que o provedor de serviços é notificado, ainda que extrajudicialmente, passa a incidir responsabilidade solidária com o autor caso não promova a remoção.

A crítica feita a esse sistema é a mesma que foi feita anteriormente. Não se deve atribuir a uma empresa privada o ônus de avaliar juridicamente se a notificação do ofendido é ou não procedente. Conforme já dito anteriormente, a empresa prestadora de serviços na Internet tem como prioridade a proteção da imagem e do faturamento da empresa, não estando comprometida com a efetividade do direito humano à liberdade de expressão, nem é tecnicamente competente para interpretar a legislação de acordo com os princípios e standards internacionais na matéria. Diante de uma notificação de um usuário ofendido, a empresa tenderá, em caso de dúvida (ou mesmo na ausência de dúvida), a retirar o conteúdo de circulação, por questões de segurança, a fim de prevenir qualquer responsabilização judicial.

Com efeito, o Relator Especial das Nações Unidas para Liberdade de Opinião e Expressão critica o sistema de notificação-e-retirada e propõe um sistema de notificação judicial.

Os usuários que são notificados pelo prestador do serviço que o seu conteúdo foi sinalizado como ilegal frequentemente têm poucos meios ou poucos recursos para contestar a retirada. Além disso, os intermediários, como entidades privadas, não estão na melhor posição para tomar a decisão de saber se um determinado conteúdo é ilegal, o que requer cuidadoso equilíbrio de interesses concorrentes e a consideração das defesas. [...] O Relator Especial acredita que medidas de censura nunca devem ser delegadas a uma entidade 
privada, e que ninguém deve ser responsabilizado por conteúdo na Internet do qual não é o autor. [...] [O] Relator Especial recomenda aos intermediários para: apenas implementar restrições a esses direitos após intervenção judicial; ser transparente para com o usuário envolvido acerca das medidas tomadas e, se for o caso, para com 0 público em geral; fornecer, se possível, aviso prévio a usuários antes da implementação das medidas restritivas; e minimizar o impacto das restrições estritamente ao conteúdo envolvido. Finalmente, deve haver recursos eficazes para os usuários afetados, incluindo a possibilidade de apelar por meio dos procedimentos previstos pelo intermediário e por uma autoridade judiciária competente (tradução livre, UNITED NATIONS, 2011, p. 12-14) ${ }^{6}$.

Por isso, as organizações de defesa de direitos humanos sustentam que a exigência de remoção de conteúdos por parte de intermediários somente pode advir de uma decisão judicial, ou de uma autoridade administrativa independente. Somente quando descumprida a decisão judicial ou administrativa é que ficaria caracterizada a responsabilidade desse intermediário. Esse é também o entendimento de Nancy Andrighi:

Em primeiro lugar, noto que essa forma de restrição, se cabível, haverá de emanar sempre de ordem judicial, mostrando-se inviável a simples notificação extrajudicial, diante da impossibilidade de se delegar o juízo acerca do potencial ofensivo de determinado texto ou imagem à discricionariedade da vítima ou do provedor (ANDRIGHI, 2012, p. 72).

O Marco Civil da Internet (Lei oㅜ 12.965/2014) assimilou esse raciocínio.

Seu art. 19 é bastante explícito na sua intenção de evitar a censura e determina que:

Art. 19. Com o intuito de assegurar a liberdade de expressão e impedir a censura, o provedor de aplicações de internet somente poderá ser responsabilizado civilmente por danos decorrentes de conteúdo gerado por terceiros se, após ordem judicial específica, não tomar as providências para, no âmbito e nos limites técnicos do seu

\footnotetext{
6 "Users who are notified by the service provider that their content has been flagged as unlawful often have little recourse or few resources to challenge the takedown. Furthermore, intermediaries, as private entities, are not best placed to make the determination of whether a particular content is illegal, which requires careful balancing of competing interests and consideration of defences. [...] The Special Rapporteur believes that censorship measures should never be delegated to a private entity, and that no one should be held liable for content on the Internet of which they are not the author. [...] [T] he Special Rapporteur recommends intermediaries to: only implement restrictions to these rights after judicial intervention; be transparent to the user involved about measures taken, and where applicable to the wider public; provide, if possible, forewarning to users before the implementation of restrictive measures; and minimize the impact of restrictions strictly to the content involved. Finally, there must be effective remedies for affected users, including the possibility of appeal through the procedures provided by the intermediary and by a competent judicial authority".
} 
serviço e dentro do prazo assinalado, tornar indisponível o conteúdo apontado como infringente, ressalvadas as disposições legais em contrário.

Portanto, ante o advento de um novo marco legal, espera-se que a jurisprudência brasileira se reposicione acerca dessa questão.

A organização não governamental Artigo XIX defende a adoção de um sistema de notificação e notificação (notice-to-notice), pelo qual os intermediários transmitem ao usuário autor do conteúdo qualquer notificação sobre a suposta ilicitude ou caráter ofensivo da sua publicação. O objetivo é obter uma manifestação do usuário e, assim, obter uma autorização voluntária de retirada de conteúdo, ao mesmo tempo em que se assegura um mínimo de contraditório. A ONG admite, porém, que esse sistema somente seria aplicável em alguns casos (<http://www.article19.org/data/files/Intermediaries_ENGLISH.pdf>).

De qualquer forma, recomenda-se aos intermediários a adoção de uma política de transparência, divulgando ao público suas condições de serviço, o que a empresa considera ou não considera publicação ofensiva, em consonância com os standards internacionais em matéria de liberdade de expressão. Devem também tornar públicas todas as notificações ou ordens judiciais de retirada de conteúdo, informando a sua quantidade e o respectivo fundamento. Um exemplo dessa boa prática é Google Transparency Report (ORGANIZACIÓN DE LOS ESTADOS AMERICANOS, 2013, p. 55).

\section{Considerações finais}

Conforme dito na introdução, o presente artigo teve por objetivo traçar um panorama da visão das organizações internacionais, especificamente a ONU e a OEA, sobre os princípios regentes do direto humano à liberdade de expressão aplicados à Internet. Constatou-se que, na ótica dessas organizações, a Internet possui características singulares, enraizadas em sua arquitetura, que devem ser levadas em conta ao se conceber normas destinadas a regulá-la, especialmente seu caráter privado, operado por empresas, radicalmente descentralizado e aberto, incompatível com uma gestão centralizada. 
Constatou-se também que, a despeito de suas características distintivas, os princípios tradicionalmente aceitos sobre liberdade de expressão continuam aplicáveis em seu sentido geral. Isso significa que o direito à liberdade de expressão na Internet é essencial para a democracia e o exercício da liberdade individual, mas que não é um direito absoluto. Porém, qualquer limitação ao direito de expressar opiniões e ideias na Internet deve satisfazer requisitos exigentes: previsão objetiva e taxativa em lei; finalidade legítima; necessidade; e proporcionalidade, além da possibilidade de recurso contra decisões restritivas perante uma autoridade independente, em consonância com 0 devido processo legal.

Em relação aos aspectos específicos da Internet, viu-se que as organizações internacionais analisadas consideram de fundamental importância o princípio da neutralidade da rede, a fim de garantir um ambiente competitivo e de incentivo à inovação, embora reconheçam, relutantemente, a possibilidade de flexibilizar esse princípio e realizar a gestão do tráfego de modo a viabilizar determinados tipos de serviços. Todavia, nesses casos, exige-se que a gestão do tráfego seja transparente e orientado a finalidades legítimas.

Com relação às medidas de filtro ou bloqueio de conteúdo por autoridades públicas, somente são admitidas como medida excepcional, a fim de coibir a pornografia infantil ou a veiculação de discursos de ódio nacional, étnico ou religioso, ou ainda de incentivo ou apologia à violência, e que não é admissível o bloqueio ou interrupção do acesso à Internet por motivos de ordem pública, ou na tentativa de desarticular ações de protesto ou resistência por parte da sociedade civil.

Outro ponto destacado pelas organizações internacionais é a necessidade de proteger o intermediário da responsabilidade por conteúdo criado ou publicado por terceiros usuários que utilizam seus serviços. As empresas prestadoras de serviços de conexão, de busca ou de plataformas de comunicação não podem ser induzidas a exercer vigilância ou monitoramento do que os seus usuários publicam, nem respondem objetivamente em caso de conteúdo ofensivo ou ilegal. Além disso, tanto a ONU quanto a OEA criticam os sistemas de notificação e retirada (notice and take down), uma vez que transferem a atores privados o dever de avaliar o caráter ofensivo ou ilegal dos 
conteúdos publicados por usuários, realizando uma censura privada incompatível com a proteção plena à liberdade de expressão.

No que se refere ao direito brasileiro, observa-se que a aprovação recente do Marco Civil da Internet (Lei no 12.965/2014) incorporou os pontos de vista expressos pelas organizações internacionais analisadas. Especificamente, em relação à responsabilização dos intermediários, observouse que a jurisprudência brasileira inicialmente adotou o ponto de vista contrário de responsabilizar objetivamente as empresas prestadoras de serviços, nos termos do direito do consumidor. Posteriormente, essa jurisprudência evoluiu no sentido de reconhecer a ausência de obrigação de monitoramento ou controle prévio de conteúdo por parte dessas empresas, mas assimilou a sistemática de notificação extrajudicial. No entanto, com o advento do Marco Civil da Internet, espera-se que a jurisprudência seja obrigada a uma nova mudança no sentido de que somente por ordem judicial se pode exigir a retirada de conteúdo da rede, sob pena de responsabilidade da empresa prestadora, conforme dispõe o art. 19 do referido diploma legal.

\section{Referências}

ANDRIGHI, Nancy. A responsabilidade civil dos provedores de pesquisa via Internet. In: Revista do TST. Brasília, vol 78, n. 3, jul/set. 2012. p. 64-75.

ARTICLE XIX. Internet intermediaries: dilemma of liability (2013). Disponível em: <http://www.article19.org/data/files/Intermediaries_ENGLISH.pdf>. Acesso em: 16/09/2014.

BRASIL. Superior Tribunal de Justiça. REsp 1.300.161/RJ. Rel. Min. Nancy Andrighi. Julgado em 19/06/2012. Disponível em:

<http://www.stj.jus.br/SCON/pesquisar.jsp>. Acesso em: 16/09/2014.

. Superior Tribunal de Justiça. REsp 1.193.764/SP. Rel. Min. Nancy Andrighi. Julgado em 14/12/2010. Disponível em: <http://www.stj.jus.br/SCON/pesquisar.jsp>. Acesso em: 16/09/2014.

. Superior Tribunal de Justiça. REsp 1.323.754/RJ. Rel. Min. Nancy Andrighi. Julgado em 19/06/2012a. Disponível em: <http://www.stj.jus.br/SCON/pesquisar.jsp>. Acesso em: 16/09/2014. 
FELITI, Guilherme. Netflix fecha acordo de interconexão com a Verizon para melhorar seu serviço. Época Negócios, 29/04/2014. Disponível em:

http://colunas.revistaepocanegocios.globo.com/tecneira/2014/04/29/netflixfecha-acordo-de-interconexao-com-a-verizon-para-melhorar-seu-servico/. Acesso em: 30/04/2014.

HABERMAS, Jürgen. Direito e democracia: entre facticidade e validade. Vol II. Trad. De Flávio Beno Siebenneischler. Rio de Janeiro: Tempo Brasileiro, 1997.

ORGANIZACIÓN DE LOS ESTADOS AMERICANOS. Comisión Interamericana de Derechos Humanos. Relatoria Especial para la Libertad de Expresión.

Marco jurídico interamericano sobre el derecho a la libertad de expresión (2009). Disponível em:

http://www.oas.org/es/cidh/expresion/docs/publicaciones/MARCO\%20JURIDIC O\%20INTERAMERICANO\%20DEL\%20DERECHO\%20A\%20LA\%20LIBERTA D\%20DE\%20EXPRESION\%20ESP\%20FINAL\%20portada.doc.pdf. Acesso em: 16/09/2014.

. Comisión Interamericana de Derechos Humanos. Relatoria Especial para la Libertad de Expresión. Declaración conjunta sobre libertad de expresión e Internet (2011). Disponível em:

http://www.oas.org/es/cidh/expresion/showarticle.asp?artID=849\&IID=2. Acesso em: 16/09/2014.

. Comisión Interamericana de Derechos Humanos. Relatoria Especial

para la Libertad de Expresión. Libertad de Expresión y Internet (2013).

Disponível em:

http://www.oas.org/es/cidh/expresion/docs/informes/2014 0408 Internet WE B.pdf. Acesso em: 16/09/2014.

MINAS GERAIS. Tribunal de Justiça. Apelação Cível no 0985391-

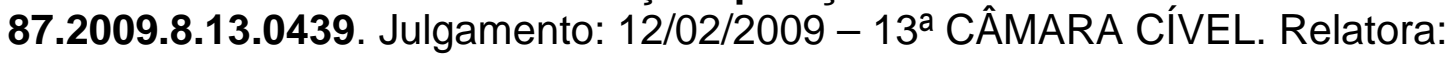

Des. Cláudia Maia. Disponível em: <http://www.tjmg.jus.br>. Acesso em: 10 mar. 2012.

. Tribunal de Justiça. Apelação Cível n 1.0105.02.069961-4/001.

Julgamento: 18/11/2008. Relator: Des. Elpídio Donizetti. Disponível em:

<http://www.tjmg.jus.br>. Acesso em: 16/09/2014.

PARANÁ. Tribunal de Justiça. Apelação Cível no 130075-8. Julgamento: 19/11/2002 - 5a CÂMARA CÍVEL. Relator: Des. Antônio Gomes da Silva.

Disponível em: <http://www.tjpr.jus.br>. Acesso em: 16/09/2014.

SÃO PAULO. Tribunal de Justiça. Apelação Cível no 0120417-

12.2005.8.26.0000. Julgamento: 22/03/2007 - Oitava Câmara de Direito Privado. Relator: Des. Salles Rossi. Disponível em:<http://www.tjsp.jus.br>. Acesso em: 16 set. 2014. 
Comarca de Franca (SP). Processo № 196.01.2006.028424-6. 2a . Vara Cível. Julgamento: 21/02/2008. Juiz: Orlando Brossi Jr. Disponível em: $<$ http://www.ibdi.org.br/site/jurisprudencia.php?id=21>. Acesso em: 16/09/2014.

UNIÃO EUROPEIA. Directiva 95/46/CE do Parlamento Europeu e do Conselho, de 24 de Outubro de 1995, relativa à protecção das pessoas singulares no que diz respeito ao tratamento de dados pessoais e à livre circulação desses dados. Disponível em: <http://eurlex.europa.eu/LexUriServ/LexUriServ.do?uri=CELEX:31995L0046:pt:HTML>. Acesso em: 16/09/2014.

UNITED NATIONS. Human Rights Council. Report of the Special Rapporteur on the promotion and protection of the right to freedom of opinion and expression - A/HRC/17/27 (2011). Disponível em: http://daccess-ddsny.un.org/doc/UNDOC/GEN/G11/132/01/PDF/G1113201.pdf?OpenElement. Acesso em 16/09/2014. p. 6-7. 